\title{
Hydrological Risk Assessment of Gibe III Dam by Using L-Moment
}

\author{
Sintayehu Yadete Tola ${ }^{1}$, Abdella Kemal ${ }^{2}$, Daniel Reddythota ${ }^{1, *}$ \\ ${ }^{1}$ Water Supply and Environmental Engineering, Arba Minch Water Technology Institute, Arba Minch University, Arba Minch, Ethiopia \\ ${ }^{2}$ Arba Minch Water Technology Institute, Arba Minch University, Arba Minch, Ethiopia
}

Email address:

dr.danielreddy1978@gmail.com (D. Reddythota)

${ }^{*}$ Corresponding author

\section{To cite this article:}

Sintayehu Yadete Tola, Abdella Kemal, Daniel Reddythota. Hydrological Risk Assessment of Gibe III Dam by Using L-Moment. American Journal of Water Science and Engineering. Vol. 5, No. 1, 2019, pp. 22-28. doi: 10.11648/j.ajwse.20190501.14

Received: January 22, 2019; Accepted: March 7, 2019; Published: April 8, 2019

\begin{abstract}
A hydrological analysis for assessing the risk of dam overtopping is required for both dam designing and dam safety checking. There is enormous amount of water to be stored in the reservoir to provide valuable service such as hydroelectric power generation and flood control. However dams can cause catastrophic damage to both life and property if they experience performance failures due to overtopping and inadequate spillway design. The hydrological risk was computed from historical peak flow data of Gilgel Gibe near Abelti, Gojeb near Shebe and Wabi near Wolkite, of major rivers flowing towards Gibe III Dam, respectively. From the flood statistics of rivers, the general extreme value (GEV) distribution was fitted to peak flow using L-moment. In this research made an attempt, the extreme event or probability of maximum discharge occurrence at dam site analyzed by associating peak occurrence with the service life of Dam and estimated the hydrological risk at Gibe III Dam. It finds PWM method is very suitable for three river flow condition flowing toward Gibe III Dam. The hydrological risk at Gibe III predicted for 50,100 and 150 years with respect of Discharge range of $2730 \mathrm{~m}^{3} / \mathrm{s}$ to $3180 \mathrm{~m}^{3} / \mathrm{s}$ was observed there is a risk decreases as return period increases.
\end{abstract}

Keywords: L-moment, Gibe III Dam, Hydrological Risk Assessment, General Extreme Value

\section{Introduction}

Flood frequency analysis and determining the design flood are the main objectives of hydrological analysis and are the basis for design of hydraulic structures and management of water resource [1, 2, 3]. Dams and Reservoirs are mainly constructed to store surplus water in wet season which can be used during dry season when the natural flow is inadequate to meet the demands. Reservoirs and dams play an essential role in controlling and harvesting benefits from floods and always pose potential risks to human life and property on their downstream side in the event of flood $[4,5,6]$. Special consideration should be given to all hydraulic structures such as dams or flood control embankment to prevent collapse of those structures. Hence an exact estimate of flood design and extreme inflow hydrographs is required for the design of such important hydraulic structures [7]. For instance, the proper design of a dam's spillway and the flood control capacity of a reservoir can ensure the safety of a dam and avoid any undesirable problems such as overtopping.

Dam floods are highly vulnerable and particularly devastating in high mountain areas, since a lack of basic data limits our understanding of the complex hydrology of mountain areas generally [8, 9]. Although particularly complex, dam flood risk evaluation can provide a rational basis for risk management, the importance of which has increasingly been recognized by both academic researchers and managers [10]. The chance of downstream flooding attributable due to uncontrolled water release from a reservoir, resulting in the loss of life and property.

Many dam failures have been recorded over the past several years attributable to overtopping and inadequate spillway design [11]. Many efforts have also been made to analyze the flood risk of dam structures. Disastrous floods can be caused by unusual combinations of hydro meteorological factors and river basin conditions [12]. A 
major issue in flood risk management studies is the assessment of probabilistic failures of the dams constructed. Hydrologic risk is the probability of failure occurring on a hydraulic structure during the service life [13]. There are two main approaches to quantitatively analyzing dam overtopping caused by flood: probabilistic risk analysis and indicatorbased risk analysis.

This research tries to identify the distribution type by using L-moment ratio graph. The suitability of the distribution type was checked with the support of Chi-square ad KolmogorovSmirnov confirms that goodness of-fit-for selected stations. To calculate the flood frequency, parameters of the fitted distribution were estimated by using PWM methods and quantile estimation was made for different return period. Hydrological risk has been predicted with the help of statistical methods [14, 20].

\section{Methodology}

\subsection{Study Area}

Omo-Ghibe River basin has an area of about 79,000 $\mathrm{km}^{2}$ and located in southwest of Ethiopia between the latitudes of $4^{0} 30^{\circ}$ and $9^{\circ} 30^{\circ} \mathrm{N}$; and longitudes of $35^{\circ}$ and $38^{\circ}$ E. The Gibe III catchment is found in the upper part of Omo-Ghibe basin which covers an area of $33,600 \mathrm{~km}^{2}$ with an average annual rainfall of $407 \mathrm{~mm}$. The average annual run-off estimated is $438 \mathrm{~m}^{3} / \mathrm{s}$. Gilgel Gibe and Gojeb Rivers are major tributaries to the main River which drains from the western high lands and Wabe River from North east, respectively. Ghibe River is known as the Omo River in its lower reaches, south-westwards from the confluence with the Gojeb River. Figure 1 shows the Gibe III watershed and its major gauging stations. The Gibe III hydropower electric dam is an extension of Gilgel Gibe I and Gibe II which have been constructed and currently, operational on the main Ghibe river.

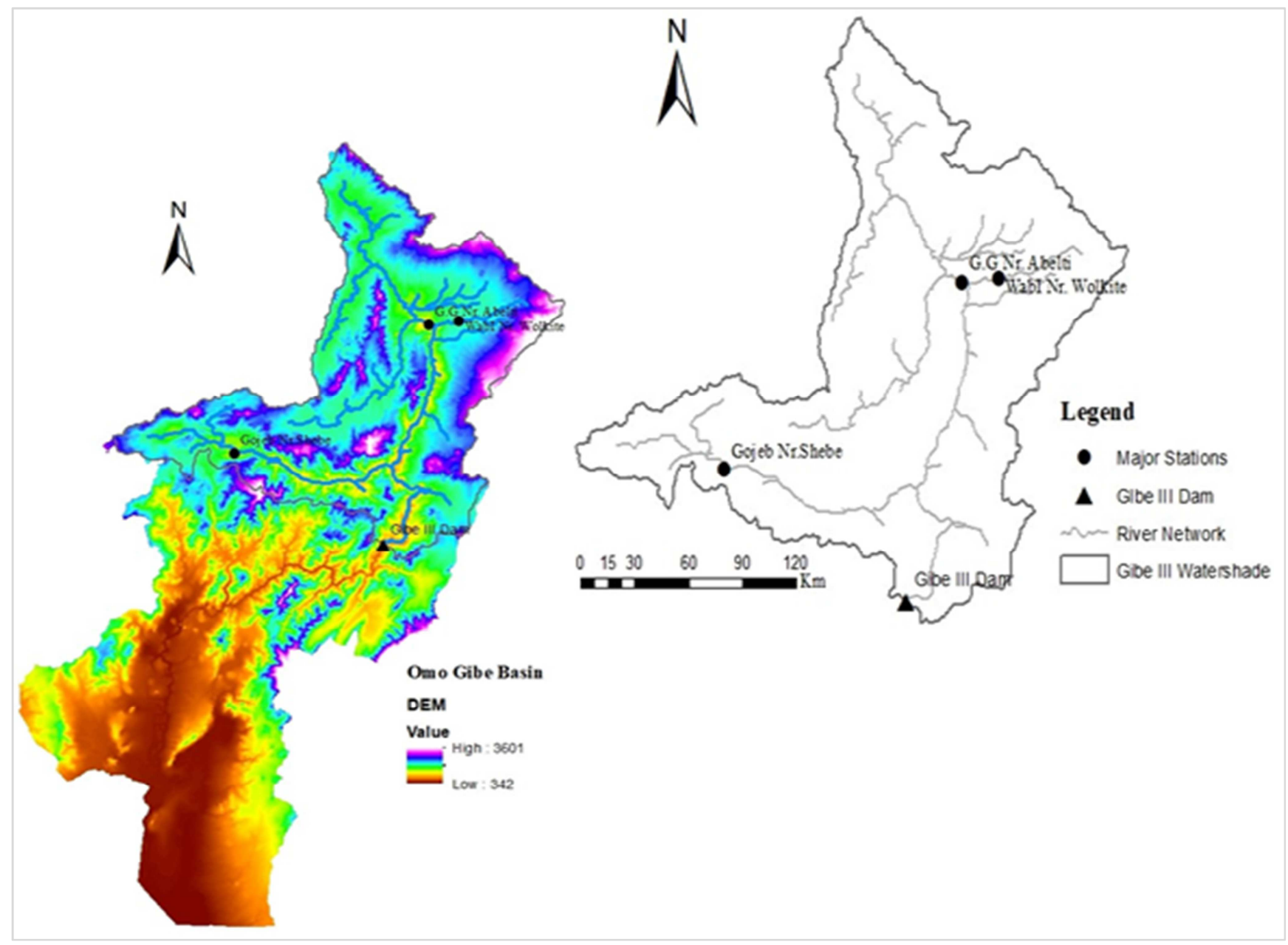

Figure 1. Omo Gibe Basin (Left) and Watershed used in this Study (Right).

\subsection{River Flow Data}

The study area- Gibe III dam site doesn't have gauging station. Gilgel Ghibe at Abelti, Wabi Nr Wolkite, and Ghibe $\mathrm{Nr}$ Shebe are the major rivers in the basin, and the hydrological risk has been carried out by pulling together the peak discharge series of Gibe-Abelti, Gojeb-Shebe and
Wolkite which are all contributing to dam. Gilgel Ghibe at Abelti station, which has high flow record (mean peak flow $=$ $\left.1017.3 \mathrm{~m}^{3} / \mathrm{sec}\right)$ and large catchment area $\left(15,467 \mathrm{~km}^{2}\right)$ compared to other. The annual flood series data assumed to be independent, random, homogeneous, and without trends. Therefore, for each gauging station, the annual maximum flow series of rivers was checked using the Wald-Wolfowitz 
Test (W-W) method for independence, the lag one Serial Correlation Coefficient (SCC) for randomness and the nonparametric Mann-Kendall (MK) and Spearman's rho (SR) statistical tests for trend at the 5\% significant level are used and a site flood frequency analysis was performed.

\subsection{L-moments}

L-moment method of flood frequency analysis is applied in determining flood magnitude of defined return periods by selecting the best-fit theoretical probability distribution. Accordingly, the flood statistics of three rivers were calculated by using L- moments. The parameter estimation for flood frequency distribution can be done using method of moment (MOM), maximum likelihood (ML), and probability weighted moment (PWM). The maximum likelihood method (MLM) is considered to be the most efficient method since it provides the smallest sampling variance of the estimated parameters with large samples and less number of parameter, but gives biased estimates. The method of moments (MOM) and PWM method are easy and simple in parameter estimation method. Parameter estimation for some distribution is unavailable with the ML or MOM method. The PWM method has recently come to be regarded as one of the best methods for parameter estimation [14, 15]. For this study, probability weighted moment (PWM) was used in estimating parameters for distributions.

L-moments can be described by PWM because it's a linear function of PWM and are defined by Hosking in terms of the PWMs $\beta$ as [16]

$$
\lambda_{r+1}=\sum_{k=0}^{r} \beta_{r}(-1)^{r-k}\left(\begin{array}{l}
r \\
k
\end{array}\right)\left(\begin{array}{c}
r+k \\
k
\end{array}\right)
$$

The first four L-moment are:

$$
\begin{gathered}
\lambda_{1}=\beta_{0}=\text { Mean flow } \\
\lambda_{2}=2 \beta_{1}-\beta_{0} \\
\lambda_{3}=6 \beta_{2}-6 \beta_{1}+\beta_{0} \\
\lambda_{4}=20 \beta_{3}-30 \beta_{2}+12 \beta_{1}-\beta_{0}
\end{gathered}
$$

The first L-moment $\lambda_{1}$, is equal to the mean series of peak flow and is a measure of location. For ranked Observed data of both three rivers and Gilgel Ghibe at Abelti, unbiased sample estimators of the PWM for any distribution were computed from equation 2-5 and substituted in L- moment equation 1 .

$$
\begin{gathered}
b_{o}=m=\frac{1}{n} \sum_{i=1}^{n} x_{j} \\
b_{1}=\frac{1}{n} \sum_{i=1}^{n-1}\left[\frac{(n-i)}{n(n-1)}\right] x_{i} \\
b_{2}=\frac{1}{n} \sum_{i=1}^{n-2}\left[\frac{(n-i)(n-i-1)}{n(n-1)(n-2)}\right] x_{i} \\
b_{3}=\frac{1}{n} \sum_{i=1}^{n-3}\left[\frac{(n-i)(n-i-1)(n-i-2)}{n(n-1)(n-2)(n-3)}\right] x_{i}
\end{gathered}
$$

Generally expressed by using equation 6 :

$$
b_{r}=\frac{1}{n} \sum_{i=0}^{n-r}\left[\frac{\left(\begin{array}{c}
n-i \\
r
\end{array}\right)}{\left(\begin{array}{c}
n-1 \\
r
\end{array}\right)}\right] x_{i}
$$

Where $x_{i}$ represents, the ranked of observed flow with $x_{i}$ the smallest and $x_{n}$ is the largest.

\subsubsection{L-moment Ratios}

Analogous to conventional moment ratios, coefficient of variation, the ratio of standard deviation and mean of a series of flood peaks, skewness and kurtosis are defined by Hosking (1990) as:

$$
\begin{gathered}
\tau=\frac{\lambda_{2}}{\lambda_{1}} \\
\tau_{r}=\frac{\lambda_{r}}{\lambda_{2}}, r \geq 3
\end{gathered}
$$

Where $\lambda_{r}, \mathrm{r}=1-4$ are L-moment, $\tau_{2}$ is a measure of scale and dispersion ( $\mathrm{LCv}), \tau_{3}$ is a measure of skewness (LCs), and $\tau_{4}$ is a measure of kurtosis (LCk).

\subsubsection{L-Moment Ratio Diagram}

L-moments moment-ratio diagram involves constructing based on the relationships between the L-moment ratios, third and fourth standardized moments (LCs versus LCk) were used as a tool to visualize, identify and select that line of best-fits distributions for the statistics of annual peak flow in the provided stations. Thus, distributions appear as single points and single curve in L-Moment Ratio Diagram.

Theoretical values of L-Cs Versus L-Ck moment ratio diagram of the most common distributions and observed maximum flow are plotted together to identify appropriate distribution type or to get the suitability of the distributions in the selected stations, it either lies close or overlaps to common distribution. Therefore, based on this, a candidate distribution is selected indicating as appropriateness to the observed data. A goodness of fit test was conducted, for assessing whether a given distribution provides an adequate fit to the regional annual maximum flood flow data.

\subsection{Hydrologic Risk Analysis}

For the purpose of risk analysis, only two, cumulative of three river data and Gilgel Ghibe at Abelti are analyzed. According to Yen (1970), an expression for the risk of failure associated with a return period and the expected life of a dam is derived. The risk of failure $\mathrm{R}$ is directly related to the return period $\mathrm{T}$. For exceedence probability $\mathrm{p}$ and nonexceedence probability $\mathrm{q}$, the hydrologic risk $\mathrm{R}$ for the occurrence of design discharge $\mathrm{X}_{\mathrm{T}}$, can be given by:

$$
R=1-(1-p)^{n}=1-q^{n}=1-\left(1-\frac{1}{T}\right)^{n}
$$

Where $\mathrm{n}=$ design life of the hydraulic structure. Therefore, the reliability, $R_{L}$, is

$$
R_{l}=1-R
$$

The non exceedence probability of a flood which is estimated by a particular distribution model can be given by 
cumulative distribution function $F(x)$. The cumulative distribution function of $\mathrm{X}$ is the area under the probability density function $\mathrm{f}(\mathrm{x})$, is given by:

$$
F(x)=\int_{-\infty}^{\infty} f(t) d t \text { for }-\infty<x<\infty
$$

If the annual maximum flood distribution is $\mathrm{F}(X q)$, the design flood quantile $X q$ corresponds to a specified value of the non-exceedance probability $\mathrm{F}(X q)$ and the nonexceedance probability is the same as the cumulative density. Therefore, the function of the given distribution can be written as:

$$
\mathrm{q}=\mathrm{F}(\mathrm{x})
$$

The fitted distribution parameters are estimated from the stochastic component of the historical data and substituting the design discharge $\mathrm{X}_{\mathrm{T}}$ for $\mathrm{x}$; it is rewritten as:

$$
\mathrm{q}=\mathrm{F}(\mathrm{Xt})
$$

The corresponding risk $\mathrm{R}$ for the $\mathrm{n}$-year period is defined by:

$$
\mathrm{R}=1-(1-\mathrm{p})^{\mathrm{n}}=1-\mathrm{q}^{\mathrm{n}}
$$

Therefore, the relationship between peak discharge and hydrological risk associated at different service life of the dam is expressed.

\section{Result and Discussion}

\subsection{Data Analyses}

The observed peak flow characteristics are shown in table 1. The test result for Stationary (KT and RS), independence (W-W) and Randomness (SCC) of all stations met the prerequisite for flood frequency analysis and confirms that

\begin{tabular}{|c|c|c|c|c|c|c|c|c|}
\hline Station & MK & RS & Upper Limit & Lower Limit & SC Coef. & W-W & Remark & \\
\hline G.G Abelti & 0.16 & 0.23 & 0.27 & -0.31 & -0.01 & 0.01 & Independent & Random \\
\hline Wabe Nr Wolkite & 1.90 & 1.89 & 0.28 & -0.33 & 0.10 & 0.86 & Independent & Random \\
\hline Gojeb Nr Shebe & 0.00 & 0.05 & 0.30 & -0.37 & 0.04 & 0.24 & Independent & Random \\
\hline Total of three River & 1.05 & 1.07 & 0.30 & -0.37 & 0.004 & 0.20 & Independent & Random \\
\hline
\end{tabular}
none of the stations are found significant trend at 5\% significant level.

Table 1. Flow characteristics of each gauging station.

\subsection{Fitted Distribution for Annual Maximum Flow of Major River}

The flood statistics of selected river in the Gibe III river basin was calculated using L-Moment method. The Lmoment ratio values were presented for three river gauging stations in Table 2, which was used to evaluate the agreement between distribution and observed data. The stochastic components of peak flow flowing at Gibe III Dam were computed by assuming that three rivers are summed and considered as a single river. The main reason to consider as Single River is that there is no recording station near and above the dam site.

Table 2. Three river gauging stations data and L-moment ratios.

\begin{tabular}{lllllll}
\hline Station Name & Area $\left(\mathbf{K m}^{\mathbf{2}}\right)$ & Years of record & Mean flow & LCv & LCs \\
\hline G.Gibe at Abelti & 15746 & 46 & 1017.28 & 0.189 & 0.002 \\
Wabe Nr Wolkite & 1866 & 41 & 403.92 & 0.226 & 0.09 \\
Ghibe Nr Shebe & 3577 & 35 & 279.72 & 0.160 & 0.211 \\
Three River & 21,189 & $35^{*}$ & 1719.32 & 0.169 & 0.192 \\
\hline
\end{tabular}

$35^{*}$ Data's were considered only for 35 year from each station when the three rivers are considered as single river flowing toward the dam.

Skewness and kurtosis coefficients of G. Gibe at Abelti of observed data is slightly closer to three rivers (which are all contributing to Gibe III Dam), this might be due to the catchment area which is more than $70 \%$ of as compared to the total of three catchments area (G. Ghibe at Abelti, Ghibe Near Shebe, and Wabe Nr Wolkite). The Coefficient variation of Wabe near Wolkite has a variation compared to Ghibe at Abelti even if these stations are very proximal. The coefficients variation range is decreasing from 0.189 to 0.160 along the downstream of Main River except that of Wabe $\mathrm{Nr}$ Wolkite station. Therefore, Catchment scale has an effect on coefficient skewness and kurtoses even if the stations are close each other.

G. Gibe at Abelti station has large catchment area and high mean annual flow but less LCs and $\mathrm{LC}_{\mathrm{k}}$ compared to the other stations and the cumulative of three rives statistics also gives less in $\mathrm{LCs}$ and $\mathrm{LC}_{\mathrm{k}}$ this might be due to the high mean flow of the rivers. Therefore, the high mean flow has less in LCs and
$\mathrm{LC}_{\mathrm{k}}$, and low mean flow has high $\mathrm{LCs}$ and $\mathrm{LC}_{\mathrm{k}}$ as present in above table 2 and as equated from equation1 and 8 [16] indicates that there is relationship between L-moments and mean flow, from the first (mean flow) to fourth moment the Lmoments values are decreasing. LCv of Three River and G. Gibe at Abelti has almost close values even if the mean flows and the catchment areas are different and the stations, Wabe $\mathrm{Nr}$ Wolkite and Ghibe Nr Shebe has different LCv and higher compared to the station that has high mean flow.

\subsection{L-moments Ratios}

Figure 2 shows L-moment ratio diagrams for the observed annual maxima flood series and commonly used probability models are plotted together. The data from Gilgel Ghibe at Abelti and the three rivers are very close to GEV model and identified as an appropriate distribution for flood frequency analysis. 


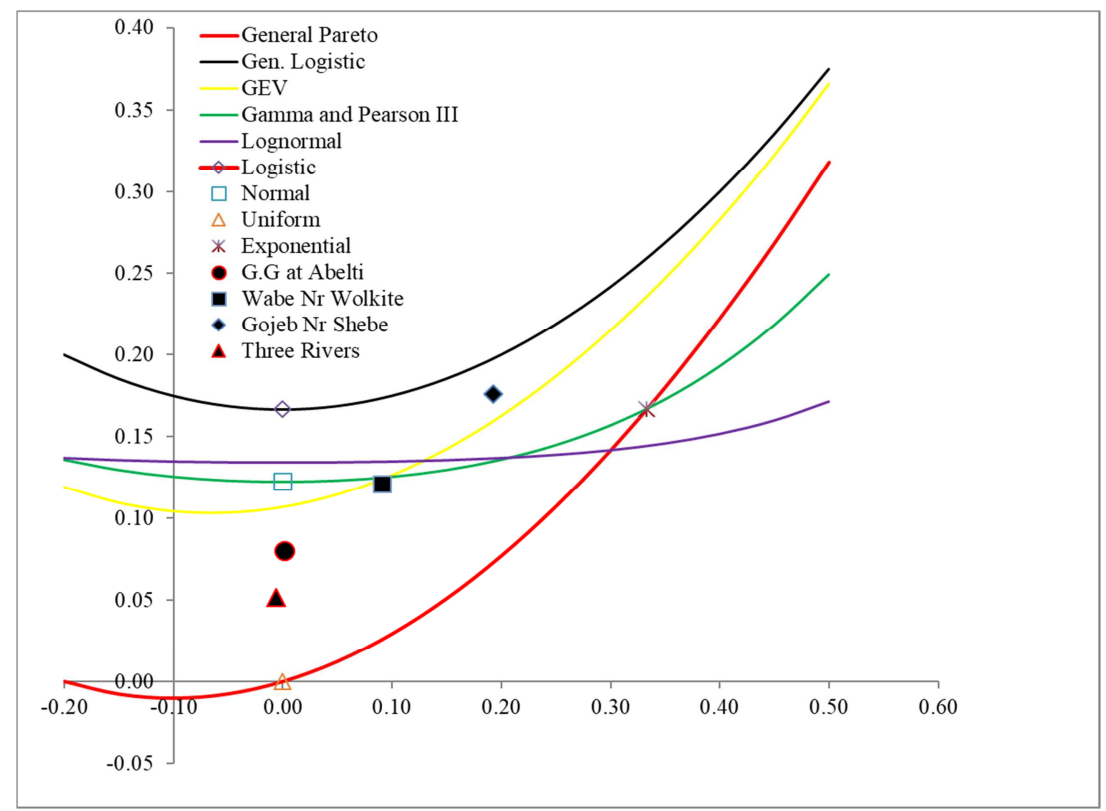

Figure 2. L-MR diagram for Annual Maxima of selected gauging stations in Gibe III Catchment for standardized flow.

From Probability model used, From $\mathrm{LC}_{\mathrm{s}}-\mathrm{LC}_{\mathrm{k}}$ moment ratio diagram, the Generalized Extreme Value (GEV) for Gilgel Ghibe at Abelti, Gojeb Near Shebe, Wabe Near Wolkite station, and Three Rivers fits better to the observed peak flow of respective stations. In selecting the probability distribution for flood frequency analysis Chi-square and Kolmogorov Smirnov tests are typical tests for goodness of fit test [17].

Using goodness of-fit- test probability distributions that adequate to annual peak flow series can be selected for further flood frequency analysis. The Chi-square and Kolmogorov Smirnov test at 5\% and 10\% significance level confidence for all data sets were done for the selected distribution model to be accepted or rejected and the statistics are presented in table 3. The chi-square and Kolmogorov Smirnov test indicates that GEV distributions are not rejected for the selected stations (Gilgel Ghibe at Abelti and total of Three Rivers). The last two rows in Table 3 gives the goodness-of-fit measure for GEV distributions for the stations as a whole. Therefore, GEV is selected as the best distribution for the stochastic component of peak flow flowing at Gibe III Dam.

Table 3. Chi-square and Kolmogrov-Smirnov Goodness of-fit-test for selected stations.

\begin{tabular}{|c|c|c|c|c|c|c|c|c|}
\hline Stations & Distribution & $\mathbf{X}^{2}$ & $\mathrm{X}^{2}$ crit $(0.05)$ & $\mathrm{X}^{2}$ crit $(0.1)$ & Dn & Dcrit (0.05) & Derit (0.1) & Remark \\
\hline G.G@Abelti & GEV & 8.9 & 12.01 & 14.1 & 0.076 & 0.20 & 0.18 & Not Rejected \\
\hline Three Rivers & GP & 2.4 & 12.59 & 10.64 & 0.060 & 0.23 & 0.21 & Not Rejected \\
\hline
\end{tabular}

X- Computed value Chi-Square statistics; $\mathrm{X}^{2}$ - Critical value at significant level; Crit - Critical; Dn: Computed value of Kolmogrov-Smirnov statistics; Dcrit: Critical value ate significant value

\subsection{Parameter and Quantile Estimation}

\subsubsection{GEV Distribution}

Since distributions that best fit to the data were selected and using the parameter estimation method, parameters for distribution were also calculated. Quantiles are estimated for different return periods for a given flood magnitude. The GEV distribution has cumulative distribution function is given by Jenkinson, 1955 equation 15 .

$$
F(x)=\exp \left\{-\left[1-k\left(\frac{x-u}{a}\right)\right]^{1 / k}\right\}
$$

The parameters $($ Location $=\mu$, Scale $=\alpha$ and shape $=\mathrm{k}$ ) of fitted distributions (GEV) was estimated by using PWM Parameter estimations method. The three river, the estimated parameters of GEV distribution using PWM are, $k=0.269, \alpha$ $=517.07$ and $\mu=1527.49$ and for Gilgel Gibe at Abelti are $k$
$=0.282, \alpha=339.93$ and $\mu=897.14$.

\subsubsection{Estimated Flood}

The primary consideration, therefore, in selection of a method for fitting, is that there will be general conformance to the data. The distribution function of $x$ given by equation 15 is written in the inverse form and the $\mathrm{T}$-year ( $\mathrm{T}$ is the return period) quantile is estimated. The estimated from the fitted distribution and observed flood quantiles at the selected stations were plotted and compared for different return periods (Figure 3) using a plotting position derived by Gringorten (1963). If observed data follows or lies close to estimated flood magnitude, it then shows a good parameter estimation method.

The relationship between observed flow and estimated flow data sets appears as curved line and then the suitability of parameters estimation method are then decided. Hence, 
PWM were chosen as the preferred estimation method for three rivers and Gilgel Ghibe at Abelti station. Therefore, the GEV distribution model of flood frequency curve conforms well to the observed data using PWM parameter estimation as shown in figure 3 and used in the subsequent risk analysis.
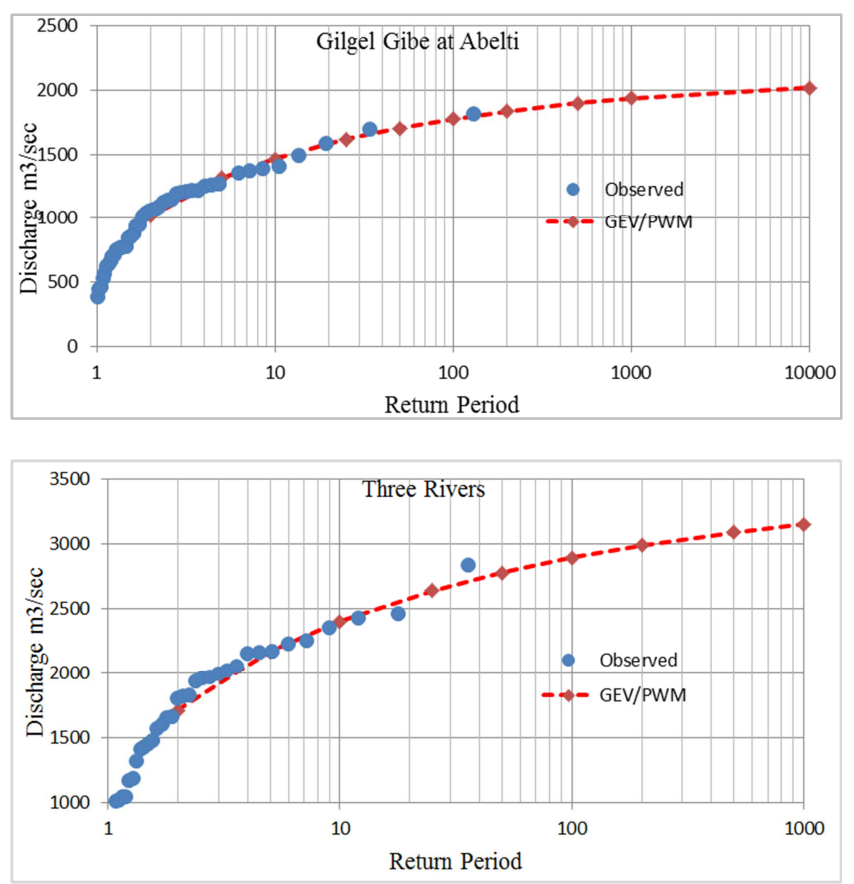

Figure 3. Comparison of actual and estimated Maximum flow quantiles of two stations using General Extreme Value distribution (GEV) using probability weighted moment estimation methods.

As shown in the above figure 3, it clearly shows that observed flow data and estimated flow almost overlap each other with GEV distribution and PWM parameters estimation method. Hosking et al. (1986) showed that the PWM method is superior to the Maximum-Likelihood (ML) method in parameter estimations when the Extreme Value Distribution is used for longer return periods and the GEV distribution has been recommended by many researchers $[18,19]$ as a smooth distribution function to describe the trend of extreme flood events. Therefore, this study confirms the above statements $[18,19]$.

\subsubsection{Hydrologic Risk Analysis}

The cumulative distribution function of the Generalized Extreme Distribution is given by Rao and Hamed (2000):

$$
F(x)=\exp \left\{-\left[1-k\left(\frac{x-u}{a}\right)\right]^{1 / k}\right\}
$$

Where $u, \alpha$ and $k$ are distribution parameters.

Below Figure 4 shows summary of the relationship between maximum discharge and hydrological risk associated at different service life of the dam.

In the above figure 4, the hydrological risks were calculated for different design life of dam 50, 100 and 150 years. For instance, the hydrologic risk was found to be $63.4 \%$ for a flood having a return period of 100 years. Practically, this result means that the probability of a flood with a 100-year return period occurring in 100 years of service life is $63.4 \%$ and for 50 years of return period, the risk is high, this is because of the shorter of return period and peak flow of three rivers is $2834.79 \mathrm{~m}^{3} / \mathrm{sec}$, thus as the probability occurrence of peak flow to the Gibe III dam (as total of three rivers) will be high. Therefore, Hydrological Risk is decreasing as return period is increasing, but the values of risk are different at different service life of dam.

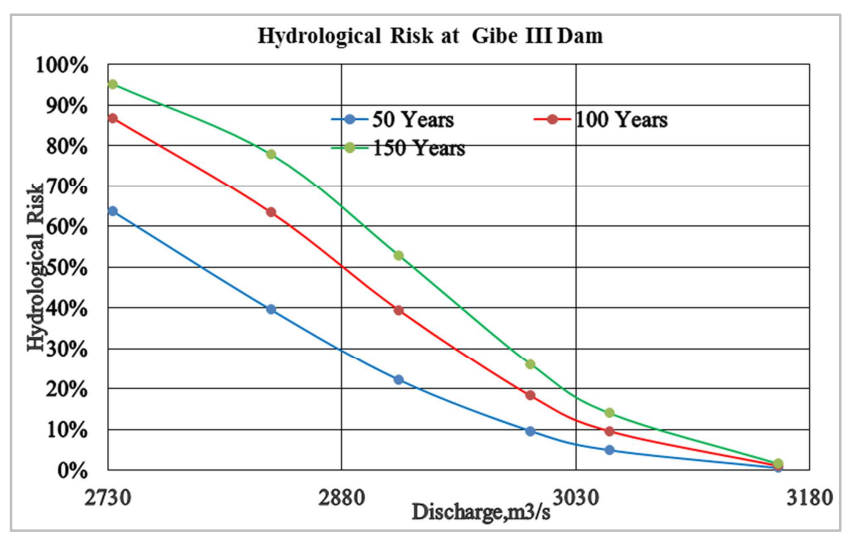

Figure 4. Relationship between hydrological risks and occurrence extreme discharge at Gibe III Dam.

\section{Conclusion}

The hydrological risk was computed by summing up the historical peak flow data of Gilgel Gibe near Abelti, Gojeb near Shebe and Wabi near Wolkite, of major rivers flowing towards Gibe III Dam, respectively. From the flood statistics of rivers, the General Extreme Value (GEV) distribution was fitted to peak flow using L-moment. This research made an attempt; the hydrological risk at dam site was analyzed by associating peak occurrence with the service life of Dam. The estimated the hydrological risk at Gibe III Dam was found 100 year's return is $63.4 \%$ and subsequently decreasing as return period is increasing. The estimated peak flow at different return period was compared with observed data flow and identified that PWM method is very suitable for three river flow condition flowing toward Gibe III Dam.

\section{References}

[1] Luo JW, Chen LN, Liu H. (2013). Distribution characteristics of stock market liquidity. Phys A: Stat Mech Applic 382:6004-6014

[2] Stedinger, J. R.; Griffis, V. W. (2012) Flood frequency analysis in the United States: Time to update. J. Hydrol. Eng., 13, 199-204.

[3] The National Flood Risk Advisory Group. Flood risk management in Australia, National Flood Risk Advisory Group (NFRAG). Aust. J. Emerg. Manag. 2008, 23, 21-27. Luo, P.; He, B.; Takara, K.; Xiong, Y. E.; Nover, D.; Duan, W.; Fukushi, K. (2015). Historical assessment of Chinese and Japanese flood management policies and implications for managing future floods Environ. Sci. Policy, 48, 265-277. 
[4] Lave, L. B.; Balvanyos, T. Risk analysis and management of dam safety. Risk Anal. 1998, 18, 455-462.

[5] Lempérière, F. (2017). Dams and Floods. Engineering 3, 144 149.

[6] Sun, R. R.; Wang, X. L.; Zhou, Z. Y.; Ao, X. F.; Sun, X. P.; Song, M. R. (2014). Study of the comprehensive risk analysis of dam-break flooding based on the numerical simulation of flood routing. Part I: Model development. Nat. Hazards, 73, $1547-1568$

[7] Goodarzi. E, Mirzaei. M, Shui. L. T., Ziaei. M. (2011). Evaluation dam overtopping risk based on univariate and bivariate flood frequency analysisHydrol. Earth Syst. ScI. Discuss., 8, 9757-9796.

[8] Shrestha, A. B.; Wake, C. P.; Dibb, J. E.; Mayewksi, P. A. (2000). Precipitation fluctuations in the Nepal Himalaya and its vicinity and relationship with some large-scale climatological parameters. Int. J. Climatol., 20, 317-327.

[9] Tullos, D.; Byron, E.; Galloway, G.; Obeysekera, J.; Prakash, O.; Sun, Y. H. (2016). Review of challenges of and practices for sustainable management of mountain flood hazards. Nat. Hazards, 83, 1763-1797.

[10] Liu, L.; Li, X.; Xia, G. Y.; Jin, J. L.; Chen, G. W. (2016). Spatial fuzzy clustering approach to characterize flood risk in urban storm water drainage systems. Nat. Hazards, 83, 1469 1483 .

[11] Singh, M.; Kijko, A.; van den Berg, L. (2011). Seismic Risk Ranking for Large Dams in South Africa. Acta Geophys., 59, 72-90.

[12] Lu Chen, Vijay P. Singh, Guo Shenglian, Zenchao hao and Tianyuan Li. (2012) Flood Coincidence Risk Analysis using Multivariate Copula Functions. J. Hydrol. Eng., 17(6), 742755 .

[13] Erdik. T, Duricic. J, Van Gelder. P. H. A. J. M., The Probabilistic Assessment of Overtopping Reliability on Akyayik Dam. Journal of Civil Engineering, 2013, 17(7), 1810-1819
[14] Cunnane, C. (1989). "Statistical distributions for flood frequency analysis." World Meteorological Organization Operational Hydrology, Rep. No. 33, WMO-No. 718, Geneva, Switzerland.

[15] Hosking, J. R. M., Wallis, J. R., and Wood, E. F. (1985), "An Appraisal of the Regional Flood Frequency Procedure in the UK Flood Studies Report," Hydrological Sciences Journal, 30, 85- 109 .

[16] Hosking, J. R. M.: L-moments: analysis and estimation of distributions using linear combinations of order statistics, J. Royal Statis. Soc., Series B, 52, 105-124, 1990.

[17] Kite, G. W. (1977) Frequency and risk analyses in hydrology. Water Resources Publications, Fort Collins, Colorado, USA.

[18] Hosking J. R. M. (1986). The theory of probability weighted moments. Research Rep. RC 12210. IBM Research Division: Yorktown Heights, NY; 160 pp.

[19] Hosking J. R. M, Wallis J. R. (1997). Regional Frequency Analysis an Approach based on L-moments Cambridge University Press: New York.

[20] Fridolf, T., (2004). Dam Safety in a hydrological perspective: case study of the historical water system of Sala Silver Mine. Thesis (Lic.). Stockholm: KTH - Royal Institute of Technology.

[21] Yen, B. C. (1970). "Risk analysis in design of engineering projects.” J. Hydrol. Eng., ASCE, 96(HY4), 959-966.

[22] Rao, A. R., and Hamed, K. H. (2000). Flood frequency analysis, CRC Press, London.

[23] Jenkinson, A. F. (1955), "The Frequency Distribution of the Annual Maximum (or Minimum) of Meteorological Elements," Quarterly Journal of the Royal Meteorological Society, 81, 158-171. (1969), "Statistics of Extremes," Technical Note 98, World Meteorological Office, Geneva.

[24] Gringorten, I. I (1963). A plotting rule for extreme probability paper Journal of Geophysical Research. Oceans, 68, 813-814. 